\title{
Associations Between Father Absence and Age of First Sexual Intercourse
}

\author{
Jane Mendle \\ University of Oregon \\ Carol A. Van Hulle \\ University of Chicago \\ Jeanne Brooks-Gunn \\ Columbia University \\ Robert E. Emery \\ University of Virginia
}

\author{
K. Paige Harden and \\ Eric Turkheimer \\ University of Virginia \\ Brian M. D'Onofrio \\ University of Indiana \\ Joseph L. Rodgers \\ University of Oklahoma \\ Benjamin B. Lahey \\ University of Chicago
}

\begin{abstract}
Children raised without a biological father in the household have earlier average ages of first sexual intercourse than children raised in father-present households. Competing theoretical perspectives have attributed this either to effects of father absence on socialization and physical maturation or to nonrandom selection of children predisposed for early sexual intercourse into father-absent households. Genetically informative analyses of the children of sister dyads $(N=1,382$, aged 14-21 years) support the selection hypothesis: This association seems attributable to confounded risks, most likely genetic in origin, which correlated both with likelihood of father absence and early sexual behavior. This holds implications for environmental theories of maturation and suggests that previous research may have inadvertently overestimated the role of family structure in reproductive maturation.
\end{abstract}

As the rate of sexually active American teenagers has increased dramatically across the second half of the 20th century (Kotchick, Shaffer, Forehand, \& Miller, 2001), there has been a corresponding surge in investigations of teenage sexuality. Research consistently identifies family structure as one salient antecedent of earlier sexual activity in teenagers. Compared to children raised by both biological parents, children who are raised in households without their biological father present exhibit both

This work was supported by NRSA predoctoral fellowship, National Institutes of Health (NIH) Grant F31 MH074163-01A1 to Jane Mendle. Contributions by Joseph Rodgers, including development of the kinship linking algorithm, were supported by NIH Grant RO1-HD034265. Other contributions were supported by NIH Grant R01-MH053554 to Benjamin Lahey, NIH Grant RO1HD056354-01 to Robert Emery, and NIH Grant R01HD53550-2 to Eric Turkheimer.

Correspondence concerning this article should be addressed to Jane Mendle, Department of Psychology, 12227 University of Oregon, Eugene, OR 97403-1227. Electronic mail may be sent to jemendle@uoregon.edu. an earlier age of first intercourse and significantly increased rates of teenage pregnancy (Ellis et al., 2003; Hogan \& Kitagawa, 1985; Kiernan \& Hobcraft, 1997; Newcomer \& Udry, 1987; Quinlan, 2003; Wight, Williamson, \& Henderson, 2006).

A number of explanatory mechanisms have been proposed for this important association, all of which implicate environmental effects of father absence. Interpreting broad epidemiological associations between family structure and teenage sexuality can be problematic, however, because children reared in father-absent families differ from those raised in father-present households in a myriad of ways that potentially affect both family structure and sexual behavior. Therefore, the observed association could be attributable to nonrandom selection of individuals predisposed for early sexual

(C) 2009, Copyright the Author(s)

Journal Compilation $\Subset$ 2009, Society for Research in Child Development, Inc. All rights reserved. 0009-3920/2009/8005-0012 
activity into father-absent families rather than proximal environmental influences.

\section{Proposed Environmental Explanations of Father Absence}

There are multiple theoretical explanations for the association between father absence and early sexual activity. Evolutionary theories propose that a key adaptive function of early childhood is to encode information that shapes future reproductive strategies, by regulating both physical and motivational pathways of sexual behavior (Belsky, Steinberg, \& Draper, 1991; Belsky et al., 2007; Draper \& Harpending, 1982). Father absence is seen as the linchpin in a set of detrimental early childhood experiences that determine whether an individual's future mating and childrearing will be oriented toward a "quality or a quantity pattern" (Belsky et al., 1991, p. 650). Because children from fatherabsent homes observe unstable, conflicted, or stressed parental relationships, they learn that resources are scarce, people untrustworthy, and relationships opportunistic. They mature in such a way that reproduction is geared toward mating rather than parenting, tending to have accelerated sexual onset, multiple sexual partners, and erratic relationships. In contrast, children from more secure two-parent family environments allocate reproductive effort to a single partnership, later onset of sexual behavior, and greater investment in fewer offspring.

Paternal investment theory, an extension of Belsky et al. (1991), posits that the developmental pathways underlying female reproductive behavior are especially responsive to the father's family role and parenting behavior (e.g., Draper \& Harpending, 1982; Ellis, 2004; Ellis \& Garber, 2000). The quality of paternal care and level of paternal involvement in parenting is believed to influence pubertal maturation and sexual behavior independent of other stressors present in the family system. By articulating a more specific and more powerful role for father involvement, father absence correspondingly becomes more salient. Even more importantly, the characteristics of the absent father seem to determine the extent of maturational acceleration; girls from father-absent households marked by exposure to serious paternal dysfunction reach menarche ahead of either their non-father-absent sisters or father-absent girls whose fathers demonstrated more stable behavior prior to family disruption (Tither \& Ellis, 2008).

A second theoretical perspective argues that parent sexual behavior acts as a socializing force for children's sexual behavior. Parents, both explicitly and implicitly, model sexual attitudes and behaviors for their children (Kotchick et al., 2001; Thornton \& Camburn, 1987). Because adolescents reared in single-parent households may have parents engaging in sexual behavior with partners to whom they are not married, the children may be more likely to view nonmarital sexual intercourse as normative $(\mathrm{Wu} \&$ Thomson, 2001). Indeed, adolescents born to very young mothers are more likely to become teenage parents themselves (Hardy, Astone, Brooks-Gunn, Shapiro, \& Miller, 1998). Nevertheless, some studies suggest that parent-child dialogues about sexuality are associated with reduced rates of risky sexual behavior during adolescence (Stone \& Ingham, 2002; Wellings et al., 2001), although others have produced conflicting results (Huebner \& Howell, 2003).

A third theoretical perspective holds that a single-parent family structure may facilitate adolescent sexuality due to reduced parental control (Hogan \& Kitagawa, 1985; Newcomer \& Udry, 1987). Two parents may more closely monitor their children's activities and social networks, reducing opportunities for sexual activity. Alternatively, it may simply be more difficult for adolescents to challenge the limits set by two parents rather than one. These hypotheses are buoyed by a breadth of empirical findings that less parental supervision is associated with an earlier age of onset of sexual behaviors, more sexual partners, and reduced contraceptive use (Borawski, Ievers-Landis, Lovegreen, \& Trapl, 2003; Browning, Leventhal, \& Brooks-Gunn, 2005; Hogan \& Kitagawa, 1985; Huebner \& Howell, 2003; Mandara, Murray, \& Bangi, 2003; Wight et al., 2006). In fact, girls who come from households with greater parental monitoring are more likely to consider timing of first intercourse "just right," a notable finding given that the vast majority of sexually active adolescent girls consider their initial sexual encounter too early (Cotton, Mills, Succop, Biro, \& Rosenthal, 2004).

\section{Potential Selection Factors}

There is reason to believe that the correlation between father absence and early offspring sexual initiation reflects confounded genetic or environmental selection factors rather than a direct effect of father absence on sexual behavior. For example, the role of socioeconomic hardship seems especially pertinent, as rates of early sexual activity are highest among adolescents raised in low-socioeconomic-status (SES) families (Browning, Leventhal, \& Brooks-Gunn, 2004; Kotchick et al., 2001). Accordingly, life-course adversity models 
conceptualize early sexual development within the framework of familial and ecological stress (Coley \& Chase-Lansdale, 1998; Fergusson \& Woodward, 2000; Hogan \& Kitagawa, 1985), viewing father absence as a secondary element of social and environmental strain. Cumulative life exposure to poverty, violence, lack of educational opportunities, and reduced parental resources increase likelihood of early sexuality and pregnancy. Because father absence correlates with these factors, it also correlates with earlier sexual onset. A second salient environmental factor that may confound the link between father absence and early sexuality is religiosity, as some religious affiliations discourage both premarital sexual intercourse and promote traditional two-parent family structure.

Genetic factors could also function as selection factors. Timing of first intercourse is heritable (Dunne et al., 1997; Mustanski, Viken, Kaprio, Winter, \& Rose, 2007; Rowe, 2002) and further linked with timing of first pregnancy (Udry, 1979). Early first pregnancy, in turn, increases the likelihood of nonresident fathers for offspring (Gee \& Rhodes, 2003). Therefore, mothers who are genetically "at risk" for early sexual activity transmit these genes to their children and are at increased risk for raising these children without biological fathers present. This scenario is known as passive gene-environment correlation because the genetic factors that influence the timing of first sexual intercourse also affect likelihood of exposure to the putative environmental influence of father absence.

Both early sexual activity and failure to maintain monogamous relationships in adulthood can additionally be considered facets of a more general, genetically influenced externalizing syndrome (Jessor \& Jessor, 1977). Children who exhibit externalizing behaviors early in life display elevated rates of both early and risky sexual behavior during adolescence (e.g., Bardone, Moffitt, Caspi, Dickson, \& Silva, 1996; Woodward \& Fergusson, 1999), and individuals who become adolescent parents are significantly more likely to have engaged in serious delinquent acts (Emery, Waldron, Kitzmann, \& Aaron, 1999; Gillmore, Lewis, Lohr, Spencer, \& White, 1997; Stouthamer-Loeber \& Wei, 1998). In adults, antisocial behavior predicts nonresidential paternity (Jaffee, Moffitt, Caspi, \& Taylor, 2003), severe marital conflict (Smith \& Farrington, 2004), and subsequent divorce (Champion, Goodall, \& Rutter, 1995). The association between father absence and early sexual activity, therefore, may be due to transmission of externalizing-related genes from parent to child. In fact, shorter alleles of the
$\mathrm{X}$-linked androgen receptor $(A R)$ gene have been associated with aggression, impulsivity, high number of sexual partners, and divorce in males and with earlier ages of physical maturation in females (Comings, Muhleman, Johnson, \& MacMurray, 2002; but see Jorm, Christensen, Rodgers, Jacomb, \& Easteal, 2004, for a failure to replicate).

\section{Comparing the Children of Sisters}

Given the breadth of potential genetic and environmental confounds, it is difficult to discriminate the extent to which father absence influences timing of sexual behavior, independent of related factors. Many studies have found that this association persists even after controlling for variables such as race/ethnicity, SES, neighborhood qualities, and parental monitoring (Day, 1992; Devine, Long, \& Forehand, 1993; Miller et al., 1997; Upchurch, Aneshensel, Sucoff, \& Levy-Storms, 1999). Nevertheless, it is impossible to control for all potentially relevant covariates in statistical analyses, especially genetic factors. One solution is to use a quasi-experimental design that can distinguish genetic and environmental influence, such as comparisons of the offspring of biological sisters.

Comparing the children of sisters who vary in their level of genetic relatedness controls for the environmental and genetic factors that are shared by siblings (Dick, Johnson, Viken, \& Rose, 2000). Suppose Sister A raises her children without a biological father present in the household, but Sister B raises her children in a father-present household. If father absence influences timing of sexual behavior independent of correlates, we would expect only the children of Sister A to display accelerated rates of first intercourse because only they have been exposed to the critical environmental stimulus. But if the association is mediated by some environmental or genetic risk, the two sisters should have children who manifest roughly comparable ages of first sexual activity. A similar design (comparing the children of twins) has been successfully employed to investigate associations between various aspects of child adjustment and environmental predictors such as marital conflict (Harden et al., 2006), adolescent motherhood (Harden et al., 2007), stepfather presence (Mendle et al., 2006), harsh punishment (Lynch et al., 2006), divorce (D'Onofrio et al., 2005, 2006), parental schizophrenia (Gottesman \& Bertelsen, 1989), and parental alcohol problems (Jacob et al., 2003).

The present study uses offspring of sister dyads to discriminate among the several plausible 
explanations for the association of paternal absence and earlier age of first sexual intercourse. Because the sister dyads (and, correspondingly, their offspring) differ in their level of genetic relatedness, they vary both in their exposure to father absence and in their exposure to potential confounding variables, either genetic and environmental in origin. By accounting for these uncontrolled confounds in data from a large and diverse population-based sample, this method allows a more accurate assessment of the extent to which father absence influences the timing of offspring's first intercourse.

\section{Method}

\section{Participants}

Mothers. Data on the maternal generation of sister dyads come from the National Longitudinal Study of Youth (NLSY79), a study originally funded by the Bureau of Labor Statistics to investigate the U.S. workforce. Data collection began with a probability sample of adolescents aged 1421 years, randomly selected through a multistage, stratified design using counties, census block groups, and enumeration districts as sampling units, followed by a screening of nearly 75,000 households. Of the 12,781 adolescents identified in 1978 as eligible for the study, 11,406 were interviewed in 1979 (90\%). This included an oversampled group of minority and economically disadvantaged youth. NLSY79 participants were reinterviewed annually through 1994 and biennially from 1994 to the present. Retention rates during follow-up assessments were $90 \%$ or better during the first 16 waves and have remained above $80 \%$ since then. Particularly relevant for the current analyses, data were collected on all qualified adolescents residing in the sampled households at the time of assessment, meaning the NLSY79 generation can be organized into sister pairs (as shown in Figure 1). In some households, first cousins were reared together as siblings; for simplification purposes, we refer to all participants raised in the same household as "sister" pairs.

Offspring. Beginning in 1986, biennial assessments of the biological children of the females in the NLSY79 sample were conducted (termed CNLSY; children of the males in the sample were not assessed). Mothers provided information on a breadth of information about their children, including behavior, temperament, and home environment. Beginning in 1994, CNLSY offspring aged

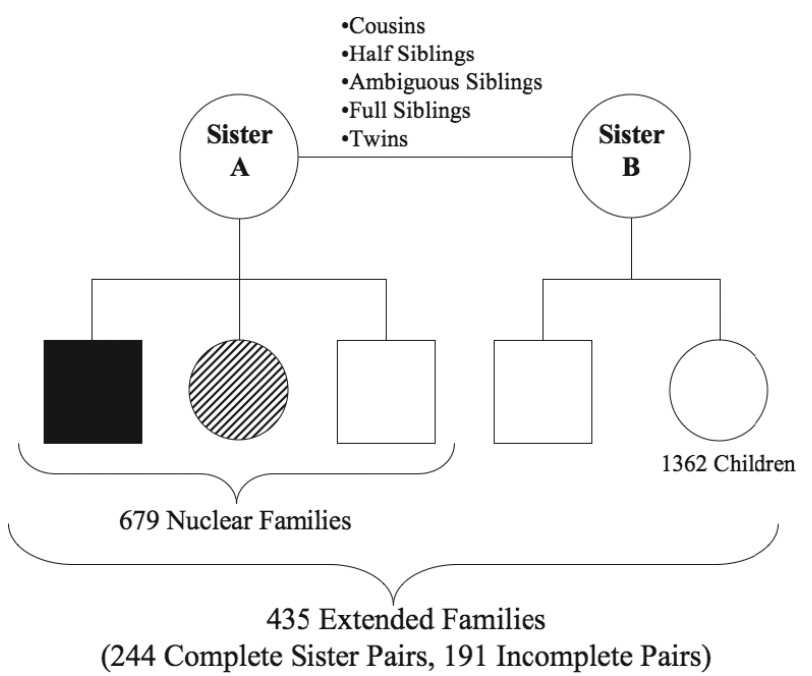

Figure 1. Organization of NLSY79 and CNLSY samples.

Note. Circles represent females; squares represent males. Number of children per nuclear family ranged from 1 to 9 . Solid black fill represents always father absence; broken black fill represents partial father absence.

14 years and older were directly interviewed every 2 years on family interactions, substance abuse, delinquent activities, and other aspects of the transition to adulthood, including age of first sexual intercourse. The current analyses investigate age of first intercourse in a CNLSY subsample, termed the offspring of sister pairs, who were at least 14 years old by the 2006 assessment and whose mothers had sisters raised in the same household of origin. This subsample comprises 1,382 offspring (691 male, 691 female) born to 679 mothers from 435 NLSY79 households of origin (488 mothers from 244 complete sister pairs and 191 mothers whose sisters did not participate in CNLSY follow-up). Age in this subsample ranged from 14 to 33 years old at the 2006 assessment $(M d n=21$ years, $S D=3.9$, mode $=17$ years). It should be noted that although the maternal generation of the NLSY is a nationally representative group of adolescents aged 14-21 in 1979, their offspring, whose outcomes are the focus of this project, would not be considered representative until all offspring are born (Chase-Lansdale, Mott, Brooks-Gunn, \& Phillips, 1991).

\section{Measures}

Father absence. The NLSY79 mothers reported at each assessment whether each child's biological father was absent or present in the household in which their children were being raised. From these longitudinal data, we constructed a category of biological father absence to indicate whether children 
were raised without fathers in the household since birth (termed always absent; $N=345,25.0 \%$ ); raised with fathers who were absent for some time after birth and before age 14, when the young adult interview replaced the maternal interview as an assessment (partially absent; $N=360,26.0 \%$ ); or raised with fathers present in the household from birth until age 14 (always present; $N=615,44.5 \%$ ). The remaining 62 children $(4.5 \%)$ had missing data for father absence. Although we could have dichotomized our measure of father absence, we chose to include the "partially absent" category given that a dose response relation between father absence and earlier sexual activity, with longer "doses" of absence associated with greater acceleration in timing of first intercourse, has been theorized (Draper \& Harpending, 1982; Ellis, 2004) and observed in some studies (Ellis et al., 2003), but not others (McLanahan, 1999), depending on the operationalization of the father absence dose.

NLSY79 mothers also reported, for each child until the child was 13 years old, whether the child's biological father was still alive. Fifty-five children (4.0\% of the offspring of sister pairs) had fathers who were reported dead; these children were included as father absent in analyses. Nevertheless, as different theoretical perspectives posit different pathways for father absence due to death (e.g., Draper \& Harpending, 1982; Hetherington, 1972), we conducted additional analyses to verify this classification (described in Results). Similarly, mothers also reported on the presence of a stepfather in the household. Two hundred and twenty-one children $(N=119$ always father absent, $N=102$ partially father absent) had stepfathers. As stepfathering has been associated with earlier ages of menarche in girls compared to father absence alone (thereby suggesting a "more accelerative" maturation process; Ellis \& Garber, 2000; Mendle et al., 2006), we conducted an additional set of analyses on these participants.

Age of first sexual intercourse. Beginning at age 14, CNLSY offspring reported biennially whether they had ever experienced sexual intercourse and, if so, at what age this first occurred. Of the 1,382 offspring, $677(49.0 \%)$ reported having sex, 362 $(26.2 \%)$ reported never having sex, and 343 (24.8\%) had missing data values for all items related to sexual activity. Of the 677 offspring who reported ever having sex, 13 offspring had missing or invalid ( $<5$ years old) reports for age at first sex; thus, analyses on observed age at first sex were conducted using the remaining 664 offspring. For the purposes of the present study, we utilized the first report of age of first sexual intercourse, which has been documented as effective both for avoiding a "telescoping" bias, in which significant life events are reported as more recent than they actually occurred, as well as for data-inconsistencies specific to adolescent reports of sexual behavior (Upchurch, Lillard, Aneshensel, \& Li, 2002). In our offspring of sister pairs subsample, the first reported age at first intercourse correlates .97 with the average of all reported ages at first intercourse across all assessments.

Genetic relatedness. Due to the original purposes of the data collection as a labor and economic assessment, the NLSY79 did not explicitly assess the genetic relatedness between individuals raised in the same household. An algorithm organizing NLSY79 participants into kinship pairs was developed to define genetic relatedness between these individuals (Rodgers, 1996; Rodgers, Johnson, \& Bard, 2005). This algorithm has been employed by a number of published studies (e.g., Rodgers, Rowe, \& Li, 1994; van den Oord \& Rowe, 2000; Van Hulle, Rodgers, D'Onofrio, Waldman, \& Lahey, 2007) and extensively validated by comparing the biometrical structure of adult height obtained in the NLSY using this system $\left(h^{2}=.88\right)$ with that of meta-analyses demonstrating heritability of height at approximately .90 (e.g., Plomin, 1990).

Using these kinship links, genetic relatedness (i.e., the correlation between additive genes) between sister pairs was assigned according to genetic theory: .125 for cousins, .25 for half-siblings, .375 for ambiguous siblings, .5 for full siblings, and .75 for same-sex twins of unknown zygosity. The only differences between these coefficients and the standard measures of relatedness derived from a quantitative genetic model (e.g., Falconer, 1981) are that in cases in which genetic relatedness of sisters in the maternal generation cannot be ascertained, the algorithm assigned a value midway between the two possibilities. In the offspring of sister pairs subsample, there were 90 children of cousins, 32 children of half-siblings, 226 children of ambiguous siblings, 1,002 children of full siblings, and 32 children of twins. For the purposes of survival modeling, genetic relatedness was recoded as a categorical variable, where an increase of one unit corresponded to an increase in genetic correlation of .125 (cousins $=-3$, half-siblings $=-2$, ambiguous siblings $=-1$, full siblings $=0$, twins $=2$ ). Full siblings were chosen as the reference group because they were the most frequent maternal relationship.

Other measures. Four sociodemographic covariates were also included in analyses: race/ethnicity (Caucasian, African American, or Hispanic, as 
reported by the mother), offspring gender, maternal SES, and maternal age at first birth. Maternal SES was indexed using total family income (log-transformed, in 1986 dollars) when the mother was 30 years old, excluding income from unmarried partners. Maternal age at first birth was included to adjust for a well-documented selection bias in the NLSY (Lahey, Van Hulle, \& Waldman, 2006), namely, that a substantial number of children old enough to be assessed (at least 14 years), and in this case old enough to have passed through the period of initiating sexual activity, were born to women who gave birth relatively early in life (Chase-Lansdale et al., 1991).

\section{Analyses}

Descriptive means comparisons. We conducted descriptive means comparisons to examine withinnuclear family, within-extended family, and between-family associations of father absence with timing of first intercourse. As a substantial subset of participants had not yet experienced first intercourse, these comparisons were intended as a purely illustrative, preliminary investigation of the data, followed by more rigorous survival models.

As an initial step, we compared the mean age of first intercourse among children whose fathers were always absent, partially absent, or always present throughout childhood. We then incorporated information about genetic and shared environmental confounds by dividing offspring into five comparison groups (summarized in Table 3 on p. 1472):

1. Children whose fathers were always absent $(N=233)$.

2. Children whose fathers were partially absent $(N=224)$.

3. Children whose fathers were always present but whose siblings experienced father absence. This is a rare scenario $(N=29)$ but one that occasionally occurs due to age differences between siblings.

4. Children whose fathers were always present (for them and for their siblings) but whose cousins experienced father absence $(N=71)$. These cousins are the children of the mother's sister.

5. Children whose fathers were always present and whose cousins and siblings were also raised with present fathers $(N=104)$.

These five groups are in descending order of risk; that is, children raised with total father absence were considered to be at the greatest risk of earlier sexual onset whereas children raised in extended families where no child experienced father absence were at the lowest level of risk.

Our means analyses targeted three primary comparisons. First, we compared the mean age of first sexual intercourse across Groups 1, 2, and 3. These groups represent children who come from nuclear families in which father absence occurs, but who differ in their personal experience (or "dose") of father absence. Second, we investigated the mean ages of first intercourse in the offspring of maternal sister dyads discordant for father absence for their children (Groups 1, 2, 3, and 4). The offspring in these groups all come from extended families in which father absence occurs, but the children differ in whether father absence occurred within their own nuclear family. Finally, the comparison of Group 5 versus Groups 1-4 is a comparison of unrelated individuals: Do children without father absence in their extended family (siblings and cousins) have later ages of first intercourse than unrelated children who do experience father absence in their extended family?

If the experience of father absence somehow directly provokes an earlier onset of sexual behavior, only those children who directly experience father absence should display earlier ages of first intercourse (e.g., Groups 1 and 2). But, if the association between father absence and sexual behavior is mediated by either a genetic or shared environmental confound, Groups 1, 2, 3, and 4 should all display earlier ages of first intercourse, because these individuals all inherit genetic and shared environmental risks that influence this association.

Multilevel survival models. Although descriptive means comparisons are informative, they are limited in several important respects. First, data from children in the same family are not independent, which obviates an accurate computation of standard errors and inferential statistics. Second, because simple means comparisons do not capitalize on the difference in genetic relatedness among the mother-generation sister pairs, they are incapable of resolving whether family-level risks are genetic or shared environmental in origin. Third, and perhaps most important, data on age at first sex were censored: Not every child had experienced first sex by the time of the 2006 follow-up. Thus, the participants with missing data for age at first sex were those who either delayed sexual intercourse relative to peers or who were not old 
enough to have fully passed through the period of risk. Because means comparisons can necessarily only include data from individuals who report an age of first intercourse, they do not account for censored data and are necessarily biased downward. To address these concerns, we estimated a series of multilevel survival models.

Model specification. The multilevel survival models estimated in the current project were similar to the hierarchical linear models used in previous analyses of similarly structured data (e.g., D'Onofrio et al., 2005; Harden et al., 2007; Mendle et al., 2006) but did not assume the outcome variable to be normally distributed, as this assumption would be inappropriate with censored data. Rather, age at first sex was modeled with a parametric Weibull distribution, where the probability that an individual will not experience sexual intercourse by time $t$ (i.e., will "survive" as a virgin) can be expressed as follows:

$\operatorname{Pr}\left(T_{i j k}>t\right)=\mathrm{e}^{-\left(\lambda_{i j k}\right)^{\alpha}}$

That is, the probability that the age at first sex $(T)$ reported by the $i$ th child, in the $j$ th nuclear family, and the $k$ th extended family exceeds any time $t$ is a function of the child's risk for sexual intercourse $(\lambda)$ and a rate parameter $(\alpha)$. The rate parameter reflects how the risk for experiencing an event changes over time, such that estimates less than 1 indicate that the hazard decreases over time, whereas estimates greater than 1 indicate that the hazard increases over time.

Two multilevel survival models were fit. In the Phenotypic Model, a child's risk for sexual intercourse $(\lambda)$ was modeled as a function of the child's own experience of father absence (FatherChild, coded as $0=$ always father absent $[N=345], 1=$ partially father absent [ $N=360]$, and $2=$ always father present $[N=615])$. This mimics the results of a simple regression used in more typical analyses but accounts for the nonindependence among the participants in the sample. The second full model included this individual-level information but also included two additional levels incorporating family information: (a) whether the child was part of an extended family where any cousin experienced father absence (FatherExt, coded as $1=$ father presence $[N=982]$ and $0=$ father absence $[N=398]$ ) and (b) whether the child was part of a nuclear family where any sibling experienced father absence (FatherNucl, coded as $1=$ father presence $[N=792]$ and $0=$ father absence $[N=575])$. The full model can be expressed as:

$$
\begin{aligned}
\log \left(\lambda_{i j k}\right) & =\beta_{0}+\beta_{1}{ }^{*} \text { FatherExt }+\beta_{2}{ }^{*} \text { FatherNucl } \\
& +\beta_{3}{ }^{*} \text { FatherChild. }
\end{aligned}
$$

In order to reduce collinearity among predictors (see Raudenbush \& Bryk, 2002), Equation 2 was reparameterized as follows:

$$
\begin{aligned}
\log \left(\lambda_{i j k}\right)= & \beta_{0}+\left(\beta_{1}+\beta_{2}+\beta_{3}\right)^{*} \text { FatherExt } \\
& +\left(\beta_{2}+\beta_{3}\right)^{*} \underbrace{(\text { FatherNucl }- \text { FatherExt })}_{\text {FatherNuclDev }} \\
& +\beta_{3} \underbrace{*(\text { FatherChild }- \text { FatherNucl })}_{\text {FatherChildDev }} .
\end{aligned}
$$

Calculating the difference between the FatherNucl and the FatherExt variables yielded a deviation score (FatherNuclDev); this equaled 0 for children whose own father was absent from the household (either for themselves or for their siblings), and 1 for children whose own father was present but whose cousins' father was absent. Thus, the effect of FatherNuclDev tested whether children from extended families where father absence occurs, but who differ in their individual experience of father absence, had different ages at first sexual intercourse. Similarly, calculating the difference between the FatherChild and FatherNucl variables yielded a deviation score (FatherChildDev), which equaled 0 for children whose own father was absent and 2 for children whose own father was present but whose siblings had an absent father. Thus, the effect of FatherChildDev addressed whether children within father-absent nuclear families, who may differ from in their individual experiences of father absence, differed in age at first sexual intercourse from siblings.

In addition, there was an interaction between the categorical variable for genetic relatedness and the FatherNuclDev deviation score. A significant interaction effect would indicate that the magnitude of the cousin comparison depended on the biological relationship between the maternal sister pair. If the association between father absence and age at first sex were attributable to genetic confounds, then we would expect that children who experienced their own father absence would be most similar to their cousins who did not experience father absence when they share the most genes, which occurs when their mothers are twins. The degree of this similarity, however, would be expected to decrease in accordance with decreasing genetic relatedness between maternal sister pairs. (An interaction between the genetic relatedness of the maternal sister pair and the FatherChildDev deviation score 
was not estimated; this is because the biological resemblance between the two members of a maternal sister dyad would not be relevant for comparisons among the offspring of only one of these sisters.)

The following covariates were also included as statistical controls: (a) child race/ethnicity (reported in the CNLSY as African American, Hispanic, or non-Hispanic White), (b) child gender, (c) an interaction between child gender and child's own experience of father absence, (d) genetic relatedness of the maternal sister pair, (e) total family income at mother's age 30, and (f) mother's age at first birth. The main effect of genetic relatedness between maternal sister pairs was not expected to be significant (e.g., there is no reason to anticipate that children of half-sisters are more sexually precocious than children of full sisters), but it is customary to include the main effect of a variable included in an interaction.

Finally, residual variation in children's risk for initiating sexual intercourse is called a frailty. Frailty that was shared by siblings in the same nuclear family was modeled with the random effect, $\zeta_{j k}$, and frailty that was shared by cousins in the same extended family was modeled with the random effect, $\zeta_{k}$. The variances of the random effects reflect how similar biological relatives are in their ages at first sex above and beyond the similarity that can be explained with measured covariates.

Model estimation. The survival model was estimated using the Markov chain Monte Carlo method in the software program WinBUGS by the MRC Biostatistics Unit. WinBUGS employs the Gibbs sampling algorithm (Geman \& Geman, 1984) to simulate values iteratively for model parameters, given a specified prior distribution and an initial value for each parameter. The output of the Gibbs sampler constitutes a Markov chain. Under a wide set of conditions, the distribution of the Markov chain converges on the posterior distribution of parameters, that is, on the distribution of parameters given the data (Gelman, Carlin, Stern, \& Rubin, 2003). The primary advantage of using WinBUGS is its flexibility to estimate a model-in this case, a survival curve with multiple nested random effects-that would be difficult or impossible to implement in many other programs. Code and initial values for the full model are available upon request.

The fit of the full model was compared to the fit of the phenotypic model using the deviance information criterion (DIC; Spiegelhalter, Best, Carlin, \& van der Linde, 2002). Lower values of the DIC indicate better model fit. Differences between models of $>10$ DIC eliminate the model with higher DIC.

\section{Results}

\section{Descriptive Means Comparisons}

We conducted initial descriptive means comparisons to examine within-nuclear family, withinextended family, and between-family associations. Because these comparisons were intended to be purely illustrative, no inferential statistics were computed. (The role of sampling error will be assessed in the following, more rigorous, multilevel survival analyses.) In lieu of probability testing, we computed effect sizes ( $d$; Cohen, 1988) for each comparison. As a general rule, an effect size of .2 is considered small, .5 medium, and .8 large.

Notably, because the offspring differ widely in age, not all participants had experienced sexual intercourse by 2006 (see Table 1). Father-absent children were more likely to report having had sexual intercourse than father-present children: $63.2 \%$ of children whose fathers were always absent reported having had sexual intercourse $(N=240)$, compared to $52.5 \%$ of children whose fathers were partially absent $(N=228)$ and only $21.0 \%$ of children whose fathers were always present $(N=205)$. A similar pattern was evident when considering males and females separately. This might reflect a legitimate effect of father absence delaying onset of sexual behavior. Alternatively, it may be indicative of an age bias, since always father-absent children were older ( $M=23.7$ years) than always fatherpresent children ( $M=20.0$ years) and therefore had

Table 1

Proportion of CNLSY Sample Who Have Had Sexual Intercourse by Father Presence

\begin{tabular}{lccr}
\hline Ever had sex & $\begin{array}{c}\text { Total sample } \\
N(\%)\end{array}$ & $\begin{array}{c}\text { Females only } \\
N(\%)\end{array}$ & $\begin{array}{c}\text { Males only } \\
N(\%)\end{array}$ \\
\hline Always absent & & & \\
$\quad$ Yes & $240(69.6)$ & $122(68.5)$ & $118(70.7)$ \\
$\quad$ No & $105(30.4)$ & $56(31.5)$ & $49(29.3)$ \\
Partially absent & & & \\
$\quad$ Yes & $228(63.3)$ & $107(58.2)$ & $121(68.8)$ \\
$\quad$ No & $132(36.7)$ & $77(41.9)$ & $55(31.3)$ \\
Always present & & & \\
$\quad$ Yes & $205(33.3)$ & $95(31.9)$ & $110(34.7)$ \\
$\quad$ No & $410(66.7)$ & $203(68.1)$ & $207(65.3)$ \\
\hline
\end{tabular}

Note. Sixty-two offspring (31 males, 31 females) were not included because of missing data for father absence. 
more years on average to complete the transition to sexual maturity. (Children whose fathers were partially absent were comparable in age to those whose fathers are always present; $M=20.2$ years.) It should be emphasized that while we address this issue of censored data in subsequent analyses, these means comparisons necessarily only utilize data from individuals who report ages of first intercourse, which results in a downward bias of estimates.

As an initial step, we compared the mean age of first intercourse among children whose fathers were always absent, partially absent, or always present throughout childhood. Our data replicated the previously reported association between earlier ages of first sexual intercourse and father absence (Table 2). The mean observed age of first intercourse among children raised with fathers who were always absent was 15.28 , compared to 15.36 for children with fathers who were partially absent, and 16.11 for children whose fathers were present for all of childhood. This pattern of results was consistent across both genders. Effect sizes for the comparisons between the always absent and always present groups were $d=.58$ for the total sample, $d=.33$ for girls, and $d=.89$ for boys.

We next incorporated information about genetic and shared environmental confounds by dividing offspring who had a valid report for age at first sex and who had nonmissing data regarding father absence $(N=661)$ into the five previously discussed comparison groups (summarized in Table 3):

1. Children whose fathers were always absent $(N=233)$.

2. Children whose fathers were partially absent $(N=224)$.

3. Children whose fathers were always present but whose siblings experienced father absence $(N=29)$.

4. Children whose fathers were always present (for them and for their siblings) but whose cousins experienced father absence $(N=71)$.
5. Children whose fathers were always present and whose cousins and siblings were also raised with present fathers $(N=104)$.

Results from these comparisons are summarized in Table 4. Offspring in Groups 1, 2, and 3 are all from nuclear families in which father absence occurs, but these children differ in their individual experience (or "dose") of father absence. If father absence were directly related to the acceleration in age at first sex, then offspring in Group 3 should demonstrate later ages at first sex than Groups 1 and 2. If, however, genetic and environmental variables shared by siblings in the same nuclear family account for the association between father absence and earlier sex, then Group 3 should have a mean age at first sex comparable to Groups 1 and 2, which is the case in our sample. Among children from nuclear families where the father was absent for at least one sibling, children whose own fathers were always absent reported a mean age of first intercourse of 15.28 (Group 1), children whose own fathers were partially absent had a mean age of 15.36 (Group 2), and children whose own fathers were always present but whose siblings experienced father absence had a mean age of 15.03 (Group 3). These effects are consistent with the alternative hypothesis that correlated genetic or environmental risks experienced by all siblings, including those who did not experience father absence, accelerate age of first intercourse.

Offspring from Groups 1, 2, 3, and 4 all come from extended families in which father absence occurs, but the children differ in whether father absence occurred within their own nuclear family. If the relation between father absence and age at first sex were attributable to environmental or genetic variables transmitted by the mother-generation sisters, children who personally experience father absence should demonstrate comparable ages at first intercourse to their non-father-absent first cousins (i.e., the children of their mom's sister).

Table 2

Mean Age of First Sexual Intercourse by Father Status

\begin{tabular}{|c|c|c|c|c|c|c|c|c|c|}
\hline \multirow[b]{2}{*}{ Father status } & \multicolumn{3}{|c|}{ Total sample } & \multicolumn{3}{|c|}{ Females only } & \multicolumn{3}{|c|}{ Males only } \\
\hline & First sex & $S D$ & $N$ & First sex & $S D$ & $N$ & First sex & $S D$ & $N$ \\
\hline Always absent & 15.28 & 2.22 & 233 & 15.89 & 2.02 & 121 & 14.63 & 2.25 & 112 \\
\hline Partially absent & 15.36 & 2.12 & 224 & 15.90 & 1.72 & 106 & 14.88 & 2.32 & 118 \\
\hline Always present & 16.11 & 1.78 & 204 & 16.33 & 1.46 & 95 & 15.92 & 2.00 & 109 \\
\hline
\end{tabular}

Note. Means comparisons conducted using 661 of the 664 offspring with valid report of age at first sex. The remaining 3 offspring (1 male, 2 females) had missing data for father absence. 
Table 3

Father Absence Comparison Groups Incorporating Family Information

\begin{tabular}{|c|c|c|}
\hline Group & Exposure to father absence & Comparison \\
\hline 1 & Children whose fathers are always absent & Children from the same "type" ${ }^{\prime a}$ of nuclear family: Do children \\
\hline 2 & Children whose fathers are partially absent & with more father absence have earlier ages of first intercourse \\
\hline 3 & $\begin{array}{l}\text { Children whose fathers are present but whose } \\
\text { siblings experience father absence }\end{array}$ & than siblings who experience less or no father absence? \\
\hline 4 & $\begin{array}{l}\text { Children whose fathers are present but whose } \\
\text { cousins experience father absence }\end{array}$ & $\begin{array}{l}\text { Children from the same "type" of extended family: Do children } \\
\text { raised with present fathers have later ages of first intercourse } \\
\text { than their cousins who experience father absence? }\end{array}$ \\
\hline 5 & $\begin{array}{l}\text { Children whose fathers are present and whose } \\
\text { cousins experience father presence }\end{array}$ & $\begin{array}{l}\text { Children from unrelated families: Do children with no father } \\
\text { absence in their extended family have later ages at first sex than } \\
\text { children with some father absence in their extended family? }\end{array}$ \\
\hline
\end{tabular}

aBy "type" of family, we mean that offspring are raised within families in which father absence occurs, but differ in their exposure to father absence. Because we compare group means as a whole, the children in these groups come from multiple families.

Table 4

Mean Age of First Intercourse Using Family Comparison

\begin{tabular}{lcrr}
\hline Father status & First sex & $S D$ & $N$ \\
\hline Always absent for self & 15.28 & 2.22 & 233 \\
Partially absent for self & 15.36 & 2.12 & 224 \\
Always present for self, absent for sibling & 15.03 & 2.35 & 29 \\
$\begin{array}{l}\text { Present in nuclear family, absent in } \\
\text { extended family }\end{array}$ & 16.12 & 1.56 & 71 \\
Present in both nuclear and extended family & 16.39 & 1.63 & 104 \\
\hline
\end{tabular}

Among those offspring with father absence in their extended family, children who personally experience father absence have ages of first sexual intercourse approximately 1 year earlier than their non-father-absent cousins $(M=16.13$, vs. 15.28 and 15.36, as discussed earlier). This result may be attributable to either a causal role of father absence or to uncontrolled genetic differences between the NLSY79 maternal sister dyads (which are, of course, inherited by the CNLSY children). Subsequent analyses further disentangle these possible explanations.

Finally, the comparison of Group 5 versus Groups 1-4 is most closely analogous to results obtained by traditional research designs in that it is a comparison of unrelated individuals: Do children without father absence in their extended family have later ages of first intercourse than unrelated children who do experience father absence in their extended family? Children from extended families without father absence have similar ages of first intercourse ( $M=16.39$, Group 5) as children who experience father absence only in their extended family $(M=16.12$, Group 4$)$, but later ages of first intercourse than children who come from fatherabsent nuclear family (Groups 1-3: 15.28, 15.36, and 15.03 , as discussed earlier). Once again, although this finding would superficially appear consistent with a causal effect of father absence, subsequent analyses attempt to elucidate this effect in more detail, as this comparison does not include genetic controls.

\section{Multilevel Survival Models}

Results from the phenotypic model are tabulated in the left-hand columns of Table 5. As would be expected, the estimated rate parameter was $>1$ (9.42; 95\% CI $=8.84-10.08$ ), indicating that the probability that an individual will start having sex increases over time. It is important to note that the rate parameter is so large because it reflects the increase in risk from time zero, which is birth (age $=0$ years) in the current analyses. The risk of losing virginity obviously increases dramatically from infancy to late adolescence. Because the relation between the regression coefficients and age at first intercourse is not particularly straightforward, as a look back at Equations 1 and 2 makes clear, we also describe results in terms of the median ages at first sex (i.e., the age at which the probability of being sexually active is 50\%) derived from the estimated parameters.

Of the covariates included as statistical controls, a later maternal age at first birth predicted later age at first sex in offspring, and females had a later age at first sex on average than males. African American and Hispanic adolescents did not significantly differ from non-Hispanic White adolescents in timing of first intercourse, nor did maternal income predict 
Table 5

Estimated Parameters From Mutlilevel Survival Models

\begin{tabular}{|c|c|c|}
\hline Parameter & Phenotypic Model & Full Model \\
\hline \multicolumn{3}{|l|}{ Fixed effects } \\
\hline$\alpha$ (rate) & $9.75(9.03,10.56)$ & $9.75(9.05,10.55)$ \\
\hline$\beta_{0}$ (intercept) & $-26.9(-29.2,-24.7)$ & $-26.9(-29.2,-24.9)$ \\
\hline $\begin{array}{l}\text { Mother's age at } \\
\text { first birth }\end{array}$ & $-.077(-.115,-.040)$ & $-.066(-.102,-031)$ \\
\hline Mother's income & $-.111(-.243, .021)$ & $-.081(-.212, .048)$ \\
\hline African American & $.217(-.091, .538)$ & $.090(-.219, .403)$ \\
\hline Hispanic & $.067(-.274, .408)$ & $.047(-.287, .386)$ \\
\hline Female & $-.522(-.816,-.205)$ & $-.527(-.855,-.198)$ \\
\hline FatherChild & $-.456(-.800,-.043)$ & - \\
\hline $\begin{array}{l}\text { FatherChild } \\
\times \text { Female }\end{array}$ & $.102(-.139, .309)$ & - \\
\hline FatherChildDev & - & $-.310(-.869, .313)$ \\
\hline $\begin{array}{l}\text { FatherChildDev } \\
\times \text { Female }\end{array}$ & - & $.151(-.223, .495)$ \\
\hline FatherNuclDev & - & $-.311(-.737, .111)$ \\
\hline Relatedness & - & $-.059(-.202, .081)$ \\
\hline $\begin{array}{c}\text { FatherNuclDev } \\
\times \text { Relatedness }\end{array}$ & - & $.214(-.177, .605)$ \\
\hline FatherExt & - & $-1.01(-1.38,-.644)$ \\
\hline \multicolumn{3}{|l|}{ Random effects } \\
\hline $\operatorname{Var}\left(\zeta_{\mathrm{jk}}\right)$-Siblings & $.810(.528,1.14)$ & $.741(.473,1.06)$ \\
\hline $\operatorname{Var}\left(\zeta_{\mathrm{k}}\right)-$ Cousins & $<.001(.000, .007)$ & $.031(.000, .161)$ \\
\hline DIC & 3409.72 & 3399.40 \\
\hline
\end{tabular}

Note. Parameter estimates with credible intervals not including zero are in boldface type.

age at first sex. Most importantly, after including these statistical covariates, experiencing father absence continued to predict an earlier age at first sex. These predicted estimates varied significantly by gender and nonsignificantly by race/ethnicity. As an example to gauge the rough magnitude of this effect, we can look at White males born to women of median age and income: In this group, the median age at first sex predicted for the always father-absent group (16.04 years) was over a year younger than the median age at first sex predicted from the always father-present group (17.25 years). This association is consistent with previous investigations using traditional research designs that only control for measured environmental variables.

Results from the full model are tabulated in the right-hand columns of Table 5. The decrease in DIC compared to the phenotypic model equaled 10.3, indicating that including family-level information regarding father absence significantly improved overall model fit. The most notable difference between the phenotypic model and the full model was that after controlling for family-level information, the child-specific, individual effect of experi- encing father absence (FatherChildDev) was no longer significant. Children who experienced father absence for all of their lives (median $=16.05$ for males; 16.94 for females) did not demonstrate significantly earlier ages at first sexual intercourse than either children who experienced partial absence ( $M d n s=16.31$ for males, 16.95 for females) or from their siblings who experienced no absence ( $M d n \mathrm{~s}=16.58$ for males, 16.96 for females). Moreover, the interaction between FatherChildDev and child gender was not significant. In other words, the relation between personally experiencing father absence and age at first intercourse was equally negligible for both females and males. This is inconsistent with theories positing that father absence is particularly influential for female sexual development.

Second, the effect of FatherNuclDev was not significant, indicating that children who came from nuclear families where at least one sibling experienced father absence did not demonstrate earlier ages at first sex than children who had present fathers but whose cousins experienced father absence ( $M d n s$ = 16.11 for males, 16.75 for females, when the mother-generation sister pair were twins). The only significant comparison was between biologically unrelated children (FatherExt): Children from extended families where no child (sibling or cousin) experienced father absence had significantly later ages at first intercourse $(M d n s=18.09$ for males, 18.80 for females) than children who came from families where at least one child experienced father absence (see two previous paragraphs for estimates, differentiated according to type of father absence).

Overall, this pattern of results suggests that "third variable" family-level risks, correlated with the experience of father absence, best account for the observed association. These risks may be either genetic or shared environmental in origin. The magnitude and the direction of the interaction between genetic relatedness and the FatherNuclDev parameter suggest that the contrast between children whose own nuclear family experienced father absence and children whose cousins experienced father absence decreased with increasing genetic relatedness between the maternal sister pair, implying that the relevant confounds are at least partly genetic in origin.

The interaction effect is depicted, separately for males and females, in Figures 2 and 3. Estimated model parameters were used to calculate predicted survival curves for children whose own father was absent, children whose cousins experienced father 


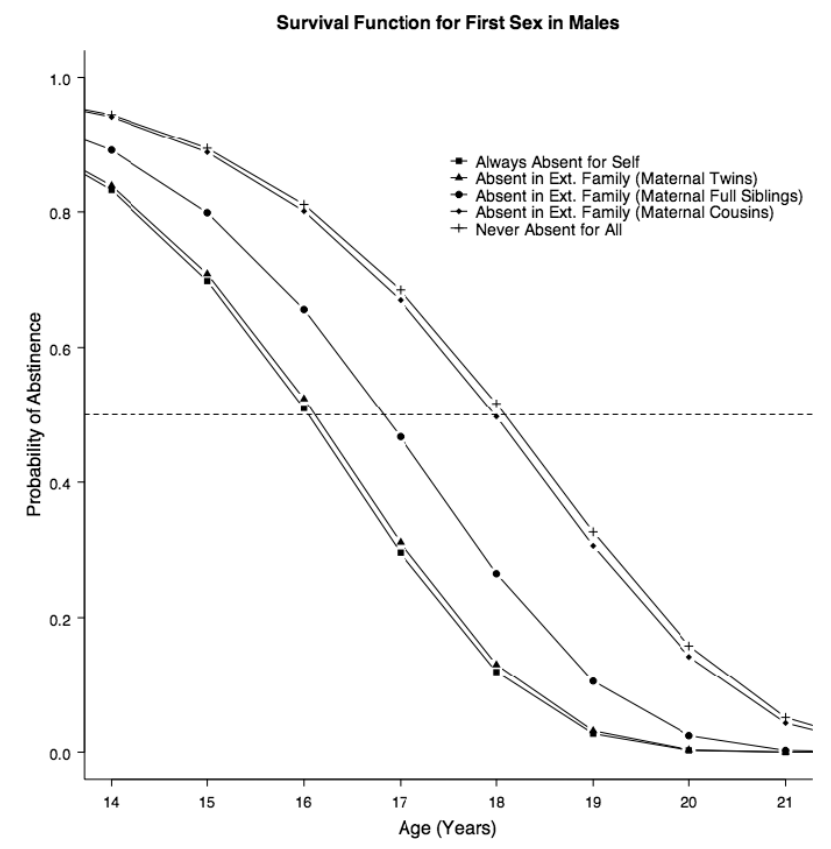

Figure 2. Probability of remaining abstinent for male offspring, by family exposure to father absence and genetic relatedness of maternal sister pair, as predicted from estimated model parameters.

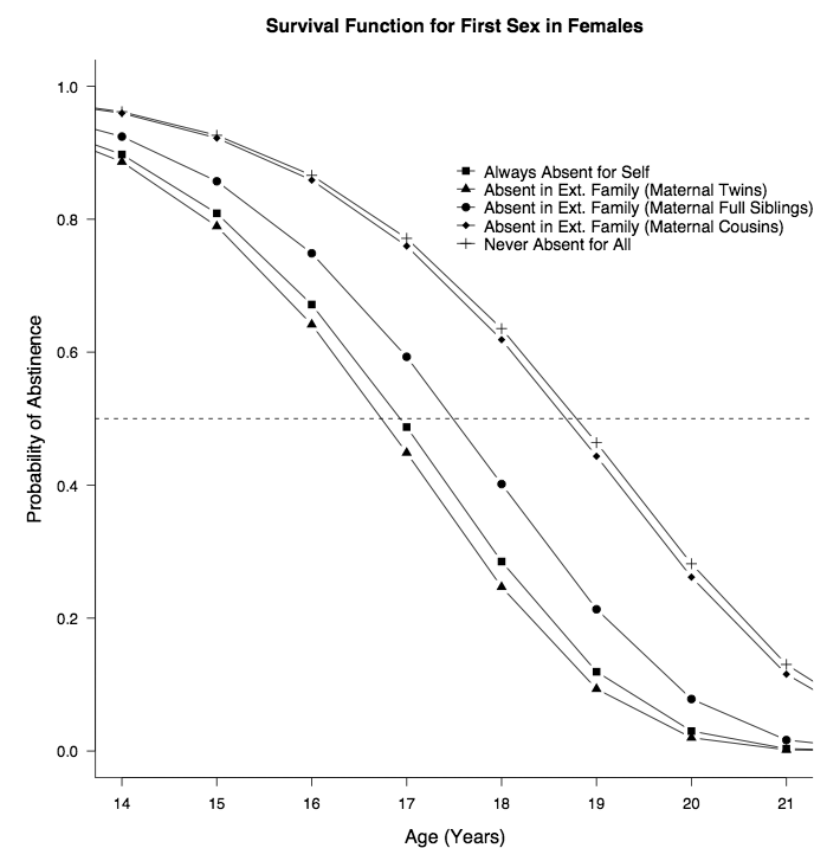

Figure 3. Probability of remaining abstinent for female offspring, by family exposure to father absence and genetic relatedness of maternal sister pair, as predicted from estimated model parameters.

Note. Ext. Family = extended family.

absence (differentiated according to the genetic relatedness of the maternal sister pair), and children who had no father absence in their extended fami- lies. Most notably, the bottom two survival curves depicted in Figures 2 and 3 are nearly identical. When we compare the children of twins, a comparison that controls for the most maternal genetic factors, children who experienced their own father absence (Absent-Self; Mdns = 16.04 for males, 16.94 for females) exhibited comparable ages of first intercourse as their non-father-absent first cousins (Absent in Extended Family [Maternal Twins]; $M d n s=16.11$ for males, 16.75 for females). In contrast, the comparison of children of mother-generation cousins controls for only $12.5 \%$ of maternal genetic factors. In this case, children who directly experienced father absence were as different from children whose cousins experienced father absence (Absent in Extended Family [Maternal Cousins]; $M d n s=17.98$ for males, 18.69 for females) as they were from unrelated children with no father absence (Never Absent for All; Mdns $=18.09$ for males, 18.80 for females). This is depicted by the top two survival curves in Figures 2 and 3. The pattern for children of full siblings was between these two extremes (Absent in Extended Family [Maternal Full Siblings]; $M d n s=16.83$ for males, 17.50 for females).

This pattern of findings is consistent with genetic mediation of the association between father absence and early age at first sex. Nevertheless, the 95\% credible interval around the interaction parameter included 0 . Although we strongly suspect that this is due to a lack of a power related for detecting this interaction (perhaps due to the small number of twin pairs in our sample), it means that we cannot conclusively state that the relevant third variable confounds are not partially shared environmental in origin.

Additional analyses. Father absence was defined in the current analyses as the biological father not residing in the same household as offspring at any time before offspring began reporting on their sexual activity at age 14 years old. Because reports of age at first sexual intercourse were retrospective, however, it would still be theoretically possible for offspring in the partial father absence group to report an age at first intercourse that preceded their age at father absence. These cases were extremely rare $(N=3)$, as would be expected given the very low prevalence of sexual activity in children younger than 13 years old. Nevertheless, we repeated the multilevel survival analyses with these offspring omitted, and generated near-identical parameter estimates as to models which included these offspring.

Second, various theoretical conceptions of the paternal role in offspring sexual development 
distinguish father absence due to separation or abandonment from father absence due to death (Draper \& Harpending, 1982; Hetherington, 1972) As mentioned in the Method section, relatively few children experienced the death of their biological father $(N=55)$. Power considerations precluded testing whether the effects of father absence due to death were different from father absence due to other reasons in our survival models. Nevertheless, it is notable that among offspring who experienced total father absence, those whose fathers had died $(N=37)$ were actually slightly more likely to have had intercourse $(78.4 \%)$ than those whose father were still alive but nonresidential (68.9\%). Moreover, the mean observed age at first sex among the always father-absent group did not differ between those with deceased fathers $(M=15.3)$ and those with alive fathers $(M=15.3)$. Similarly, among offspring who experienced partial father absence, those whose fathers had died $(N=18)$ were equally likely to have had sexual intercourse $(64.7 \%)$ as those whose fathers were absent but still alive (63.3\%). Overall, then, children with absent fathers due to separation or abandonment did not appear systematically more likely to engage in early sexual intercourse than children with absent fathers due to death. Nevertheless, we repeated the multilevel survival analyses with these 55 children omitted, and results did not differ from analyses that included these children.

Lastly, some research suggests that presence of a stepfather is more strongly associated with an earlier age of menarche in girls than father absence alone (Ellis \& Garber, 2000; Mendle et al., 2006). The current analyses do not distinguish between father absence and stepfather presence in offspring. To clarify our findings, we investigated the presence of stepfathers in our sample. Of children whose fathers were always absent, $N=119$ (34.4\%) had stepfathers entering the household at some point during childhood; of children who experienced partial father absence, $N=102(28.3 \%)$ had stepfathers. A minimally higher percentage of children with stepfathers reported having had sexual intercourse (77.3\% in always absent group, $68.6 \%$ in the partially absent group) than children without stepfathers $(76.5 \%$ in the always absent group, $64.0 \%$ in the partially absent group). The mean age of first intercourse for children with stepfathers (Ms = 15.11 for always father absent, 15.30 for partially father absent) was similar to the mean age of first intercourse for children without stepfathers (Ms = 15.30 for always father absent, 15.38 for partially father absent). These mean differences between children with and without stepfathers in the always absent group correspond to an effect size $(d)$ of .08 , substantially smaller than the effect size observed for biological father presence versus absence $(d=.58)$.

\section{Discussion}

First sexual intercourse is a significant developmental milestone, representing a confluence of personal, biological, and social factors. Children raised in father-absent households have earlier ages of first intercourse than those raised in father-present households. Competing theoretical perspectives attribute this association to various environmental mechanisms, including a psychophysiological adaptation that adjusts timing of sexual development and behavior, parental modeling of nonmarital sexual behavior, and reduced parental supervision in mother-headed households. Alternatively, this association could be due to nonrandom selection of individuals predisposed for early sexual intercourse into father-absent homes.

The results of our analyses provide new insights into the role of family structure in the onset of sexual activity. First and foremost, our analyses obtained between-family effects that dwarf all other significant model parameters. In other words, it seems that previous research may have inadvertently amplified the correlation of father absence with offspring's age of first intercourse through a failure to account fully for family-level confounds. Once we controlled for these confounds in our family-based, quasi-experimental design, the overall effect of family structure was greatly minimized. Second, there is a small, within-extended family effect that decreases in accordance with increasing genetic relatedness between the sisters. Among the offspring of sister dyads discordant for father absence for their children, those children born into father-absent nuclear families demonstrated earlier ages of first intercourse than their first cousins born into father-present families only when the children inherited different genetic factors from their mothers. When the largest possible amount of this genetic variation was controlled, in the comparison of the children of twin sisters, children born into father-absent families demonstrated virtually identical ages of first intercourse as their first cousins born into father-present families. Lastly, these within-sister findings are supported by the within-nuclear family comparison: All 
children born into nuclear families with absent fathers have early ages of first intercourse regardless of whether a child personally experiences father absence prior to sexual intercourse and regardless of the timing and/or duration of father absence. Collectively, these findings suggest that it is some genetic risk factor correlated with father absence that accelerates timing of intercourse in children rather than the distinct experience of father absence in and of itself.

There are a number of plausible mechanisms by which genetic factors might account for the association of father absence with early sexual activity. First, genes affect timing of pubertal development (Mustanski, Viken, Kaprio, Pulkkinen, \& Rose, 2004), timing of first intercourse (Mustanski et al., 2007), and age at first childbirth (Kohler, Rodgers, \& Christensen, 2002; Neiss, Rowe, \& Rodgers, 2002), which subsequently predict likelihood of nonresidential fathers for offspring (Gee \& Rhodes, 2003). Second, early sexual activity is viewed by some theorists to be one manifestation of a more general syndrome of antisocial and risky behaviors (Jessor \& Jessor, 1977). Therefore, the same genetic influences that lead individuals to engage in early sexual behavior may also affect impulsivity, tenuous interpersonal relationships, argumentativeness, substance abuse, and other behaviors that increase likelihood of father absence. These genetic influences are transmitted from parents to offspring, resulting in children at increased risk for early sexual activity growing up in father-absent families.

Despite evidence of a genetic mechanism for this association, these results are not as incongruous with theories of environmental influences of father absence as they might initially appear. This is because the social processes believed to mediate the association between father absence and offspring sexual behavior do not occur independent of genetic traits. Consider, for example, the role of parental supervision: Parents with high levels of externalizing behavior may not only be transmitting antisocial traits to their offspring but-for reasons related to their own genetic predispositions-may also be investing in only limited or sporadic monitoring of children's activities. Notably, our findings are somewhat stronger for boys compared to girls. This is incongruous with theories regarding girls' special sensitivity to paternal involvement and may reflect the higher genetic transmission for age of first intercourse in boys (Dunne et al., 1997; Mustanski et al., 2007; Rodgers, Rowe, \& Buster, 1999).

\section{Data Considerations}

Our study has several limitations worth explicating. Most importantly, we lacked sufficient statistical power to discriminate conclusively between genetic and shared environmental confounds. In general, complex behavior genetic designs require very large sample sizes to have adequate power. Relying on the relationships available in the NLSY data, which include a small proportion of twins and do not include information on twin zygosity, further compromised power. Although the pattern of findings observed through the interaction parameter (see Figures 2 and 3 ) is consistent with complete genetic mediation of the association, future research with larger data sets would be necessary to ascertain this.

Second, at this point in the ongoing CNLSY data collection, the children in our analyses who have passed through the risk period for sexual initiation were necessarily born to younger mothers. Therefore, our findings are based on a sample of adolescents born to mothers younger than the population mean. This is an issue of direct conceptual and methodological interest, since our analyses target this exact question of nonrandom selection of early sexual activity adolescents into father-absent families. The range of maternal age at first childbirth was broad enough for us to include as a covariate, but our findings may not be representative even after this adjustment. This might not be an important limitation, however, as we would expect our findings to be strengthened by the inclusion of the offspring of the older CNLSY mothers (who can be added to analyses in a few years, once the entire sample has progressed to adolescence). This is because these offspring of mothers with older ages at first birth can be expected to be less likely to have experienced father absence than the current subsample.

\section{The Children of Sisters Design}

The children of sisters design represents one of the best methodologies for eliminating familial confounds. As such, our results highlight the utility of reexamining well-established associations through a more precise data analytic strategy. Nevertheless, it should be noted that this methodology has two major limitations. First, although the children of sisters design accounts for environmental and genetic variables shared 
by maternal sister dyads, the within-sister pair association remains confounded by nonshared environmental influences, genetic differences between nontwin sisters, and, perhaps most importantly, genetic influences of the fathers on the offspring (Eaves, Silberg, \& Maes, 2005). This limitation is partially tempered by the inclusion of multiple offspring from each nuclear family; if siblings in the same nuclear family have the same father, then the comparison of children who differ in their amount of father absence controls for paternal genetic influence. Yet the number of siblings with differing experiences of father absence is extremely small in our sample. Moreover, NLSY mothers only provide information on each child's biological father, which leaves some ambiguity as to whether the offspring born to a mother share the same father. This quirk of the data ironically reinforces the strength of our findings, as we would expect more similar ages of first intercourse among offspring who are more closely genetically related; even a small component of half-siblings among our offspring would be expected to weaken the pattern of genetic transmission.

Second, individuals likely differ in their vulnerability to adverse environmental experiences. Therefore, it is possible that father absence might not accelerate sexual developmental in all children, but only in children with specific genetic vulnerabilities, a gene-environment interaction. In current models of children of sisters data, any effects due to gene-environment interaction are subsumed under genetic main effects. This is problematic, because ignoring gene-environment interaction can lead to the overestimation of genetic confounds and failure to detect withinfamily associations (Harden, Hill, Turkheimer, \& Emery, 2008). Yet a truly comprehensive model of the interplay between genetics, environmental experience of father absence, and the timing of first sexual intercourse is no easy task. Most salient for the current study, the detection of geneenvironment interaction requires very large sample sizes for adequate power, and our power is currently limited even for the detection of genetic main effects. Although future research will only clarify the mechanism by which father absence is associated with earlier sexual behavior, a model that considers only genetic confounds and not gene-environment interaction is still an improvement over the prevailing literature on this topic, which does not control for any genetic transmission.

\section{Conclusions}

These results, in many ways, may best be viewed as a preliminary foray into the larger and far more complicated riddle of how father absence affects offspring development. Above all, we believe the findings highlight two main themes: (a) the utility of genetically informed designs in the investigation of ostensibly environmental factors and (b) the need to consider a more nuanced interpretation of "father absence." With regard to methodology, the primary advantage of a genetically informed design is that it permits a reevaluation of existing theories. This is an advantage that extends well beyond the present study and can, in fact, be applied to any association of risks and outcomes. Understanding whether risk factor $X$ causes negative outcome $Y$ has traditionally presented a methodological conundrum for developmental psychopathologists. As children cannot be randomly assigned to the adverse conditions believed to produce problematic outcomes, all research in this field is, by definition, nonempirical. A more accurate understanding of proposed causal pathways holds repercussions for facilitating transitions from academic theory into intervention and practice. This is of particular resonance for relationships of the sort investigated in the present study, which have considerable implications for social policy as well as research interest.

Father absence, in both the research literature and mainstream culture, is a phrase meant to evoke a certain type of underprivileged household. Despite a universal consensus that harsh, chaotic, and impoverished environments are deleterious for children, we cannot consider father absence necessarily synonymous with these correlates in terms of developmental processes. For example, children raised in high-conflict marriages actually demonstrate greater well-being postdivorce (Booth \& Amato, 2001). Similarly, children with antisocial fathers fare more poorly and exhibit higher levels of externalizing when they are raised in the household with this father (Jaffee et al., 2003). Nevertheless, the (perhaps unintentional) implication of environmental theories of father absence is that the traditional two-parent family structure is optimal and that deviations from this form are inherently damaging to children. This raises, then, not merely an academic but also a moral quandary for developmentalists, whose findings hold considerable social and political relevance: Although many evolutionary theorists, for example, declare themselves agnostic as to the advantages of particular rearing environments, such interpretations nevertheless occur within the realm of media, 
governmental agencies, and religious organizations, independent and disconnected from the scholars who produced such work.

Investigations of teenage sexuality similarly adopt a crisis perspective, conceptualizing adolescent intercourse as pathological and damaging (Kotchick et al., 2001). Although there are clear and important risks associated with early sexual initiation, a monogamous 16 years old using contraception differs in those risks from a 13 years old (or even another 16 years old) having unprotected intercourse with multiple partners. In fact, recent findings suggest psychological sequelae of age of first intercourse differ according to context; while teenage girls who have intercourse while not involved in romantic relationships experience negative outcomes, no such effects were obtained either for boys or for girls involved in romantic relationships (Meier, 2007). There is an obvious need to understand variations in milestones such as timing of first intercourse, but a full understanding will require more nuanced examinations of how or why age at first intercourse is associated with particular predictors and outcomes.

\section{References}

Bardone, A., Moffitt, T., Caspi, A., Dickson, N., \& Silva, P. (1996). Adult mental health and social outcomes of adolescent girls with depression and conduct disorder. Development and Psychopathology, 8, 811-830.

Belsky, J., Steinberg, L., \& Draper, P. (1991). Childhood experience, interpersonal development and reproductive strategy: An evolutionary theory of socialization. Child Development, 62, 647-670.

Belsky, J., Steinberg, L., Houts, R. M., Friedman, S. L., DeHart, G., Cauffman, E., et al. (2007). Family rearing antecedents of pubertal timing. Child Development, 78, 1302-1321.

Booth, A., \& Amato, P. R. (2001). Parental predivorce relations and offspring postdivorce well-being. Journal of Marriage and the Family, 63, 197-212.

Borawski, E. A., Ievers-Landis, C. E., Lovegreen, L. D., \& Trapl, E. S. (2003). Parental monitoring, negotiated unsupervised time, and parental trust: The role of perceived parenting practices in adolescent health risk behaviors. Journal of Adolescent Health, 33, 60-70.

Browning, C., Leventhal, T., \& Brooks-Gunn, J. (2004). Neighborhood structural disadvantage, collective efficacy, \& the timing of first intercourse. Demography, 41, 697-720.

Browning, C., Leventhal, T., \& Brooks-Gunn, J. (2005). Sexual initiation in early adolescence: The nexus of parental and community control. American Sociological Review, 70, 758-778.
Champion, L. A., Goodall, G., \& Rutter, M. (1995). Behavior problems in childhood and stressors in early adult life: A 20-year follow-up of London school children. Psychological Medicine, 25, 231-246.

Chase-Lansdale, P. L., Mott, F. L., Brooks-Gunn, J., \& Phillips, D. A. (1991). Children of the National Longitudinal Survey of Youth: A unique research opportunity. Developmental Psychology, 27, 918-931.

Cohen, J. (1988). Statistical power analysis for the behavioral sciences (2nd ed.). Hillsdale, NJ: Erlbaum.

Coley, R. L., \& Chase-Lansdale, P. L. (1998). Adolescent pregnancy and parenting: Recent evidence and future directions. American Psychologist, 53, 152-166.

Comings, D. E., Muhleman, D., Johnson, J. P., \& MacMurray, J. P. (2002). Parent-daughter transmission of the androgen receptor gene as an explanation of the effect of father absence on age of menarche. Child Development, 73, 1046-1051.

Cotton, S., Mills, L., Succop, P. A., Biro, F. M., \& Rosenthal, S. L. (2004). Adolescent girls' perceptions of the timing of their sexual initiation: "Too young" or "just right"? Journal of Adolescent Health, 34, 453-458.

Day, R. D. (1992). The transition to first intercourse among racially and culturally diverse youth. Journal of Marriage and the Family, 54, 749-762.

Devine, D., Long, P., \& Forehand, R. (1993). A prospective study of adolescent sexual activity: Description, correlates, \& predictors. Advances in Behavior Research and Therapy, 15, 185-209.

Dick, D. M., Johnson, J. K., Viken, R. J., \& Rose, R. J. (2000). Testing between-family associations in withinfamily comparisons. Psychological Science, 11, 409-413.

D'Onofrio, B. M., Turkheimer, E., Emery, R. E., Slutske, W., Heath, A., Madden, P. A. F., et al. (2005). A genetically informed study of marital instability and its association with offspring psychopathology. Journal of Abnormal Psychology, 114, 570-586.

D'Onofrio, B. M., Turkheimer, E., Emery, R., Slutske, W., Heath, A., Madden, P. A. F., et al. (2006). A genetically informed study of the processes underlying the association between parental marital instability and offspring adjustment. Developmental Psychology, 42, 486-499.

Draper, P., \& Harpending, H. (1982). Father absence and reproductive strategy: An evolutionary perspective. Journal of Anthropological Research, 38, 255-273.

Dunne, M. P., Martin, N. G., Statham, D. J., Slutske, W. S., Dinwiddie, S. H., Bucholz, K. K., et al. (1997). Genetic and environmental contributions to variance in age at first sexual intercourse. Psychological Science, 8, 211-216.

Eaves, L. J., Silberg, J., \& Maes, H. (2005). Revisiting the children of twins: Can they be used to resolve the environmental effects of dyadic parental treatment on child behavior? Twin Research, 8, 283-290.

Ellis, B. J. (2004). Timing of pubertal maturation in girls: An integrated life history approach. Psychological Bulletin, 130, 920-958.

Ellis, B. J., Bates, J. E., Dodge, K. A., Fergusson, D. M., Horwood, L. J., Pettit, G. S., et al. (2003). Does father 
absence place daughters at special risk for early sexual activity and teenage pregnancy? Child Development, 74, 801-821.

Ellis, B. J., \& Garber, J. (2000). Psychosocial antecedents of variation in girls' pubertal timing: Maternal depression, stepfather presence, and marital and family stress. Child Development, 71, 485-501.

Emery, R. E., Waldron, M., Kitzmann, K. M., \& Aaron, J. (1999). Delinquent behavior, future divorce or nonmarital childbearing, \& externalizing behavior among offspring: A 14-year prospective study. Journal of Family Psychology, 13, 568-579.

Falconer, D. S. (1981). Introduction to quantitative genetics. New York: Longman.

Fergusson, D. M., \& Woodward, L. J. (2000). Teenage pregnancy and female educational underachievement: A prospective study of a New Zealand birth cohort. Journal of Marriage and the Family, 62, 147-161.

Gee, C. B., \& Rhodes, J. E. (2003). Adolescent mothers' relationship with their children's biological fathers: Social support, social strain and relationship continuity. Journal of Family Psychology, 17, 370-383.

Gelman, A., Carlin, J. B., Stern, H. S., \& Rubin, D. B. (2003). Bayesian data analysis (2nd ed.). Boca Raton, FL: CRC Press.

Geman, S., \& Geman, D. (1984). Stochastic relaxation, Gibbs distributions, and the Bayesian restoration of images. IEEE Transactions on Pattern Analysis and Machine Intelligence, 6, 721-741.

Gillmore, M. R., Lewis, S. M., Lohr, M. J., Spencer, M. S., \& White, R. D. (1997). Repeat pregnancies among adolescent mothers. Journal of Marriage and the Family, 59, 536-550.

Gottesman, I. I., \& Bertelsen, A. (1989). Confirming unexpressed genotypes for schizophrenia. Archives of General Psychiatry, 46, 867-872.

Harden, K. P., Hill, J. E., Turkheimer, E., \& Emery, R. E. (2008). Gene-environment correlation and interaction in peer effect on adolescent alcohol and tobacco use. Behavior Genetics, 38, 339-347.

Harden, K. P., Lynch, S. K., Turkheimer, E., Emery, R. E., Slutske, W. S., Waldron, M. D., et al. (2007). A behavior genetic investigation of adolescent motherhood and offspring mental health problems. Journal of Abnormal Psychology, 116, 667-683.

Harden, K. P., Turkheimer, E., Emery, R. E., D'Onofrio, B. M., Slutske, W., Heath, A., et al. (2006). Marital conflict and conduct disorder in children-of-twins. Child Development, 78, 1-18.

Hardy, J. B., Astone, N. M., Brooks-Gunn, J., Shapiro, S., \& Miller, T. L. (1998). Like mother, like child: Intergenerational patterns of age at first birth and associations with childhood and adolescent characteristics and adult outcomes in the second generation. Developmental Psychology, 34, 1220-1232.

Hetherington, E. M. (1972). Effects of father absence on personality development in adolescent daughters. Developmental Psychology, 7, 313-326.
Hogan, D. P., \& Kitagawa, E. M. (1985). The impact of social status, family structure, \& neighborhood on the fertility of black adolescent. American Journal of Sociology, 90, 825-855.

Huebner, A. J., \& Howell, L. W. (2003). Examining the relationship between adolescent sexual risk-taking and perceptions of monitoring, communication, \& parenting styles. Journal of Adolescent Health, 33, 71-78.

Jacob, T., Waterman, B., Heath, A., True, W., Bucholz, K. K., Haber, R., et al. (2003). Genetic and environmental effects on offspring alcoholism: New insights using an offspring-of-twins design. Archives of General Psychiatry, 60, 1265-1272.

Jaffee, S. R., Moffitt, T. E., Caspi, A., \& Taylor, A. (2003). Life with (or without) father: The benefits of living with two biological parents depend on the father's antisocial behavior. Child Development, 74, 109-126.

Jessor, R., \& Jessor, S. L. (1977). Problem behavior and psychosocial development: A longitudinal study of youth. New York: Academic Press.

Jorm, A. F., Christensen, H., Rodgers, B., Jacomb, P. A., \& Easteal, S. (2004). Association of adverse childhood experiences, age of menarche and adult reproductive behavior: Does the androgen receptor gene play a role? American Journal of Medical Genetics Part B: Neuropsychiatric Genetics, 125B, 105-111.

Kiernan, K. E., \& Hobcraft, J. (1997). Parental divorce during childhood: Age at first intercourse, partnership and parenthood. Population Studies, 51, 41-55.

Kohler, H., Rodgers, J. L., \& Christensen, K. (2002). Between nature and nurture: The shifting determinants of female fertility in Danish twin cohorts. Social Biology, 49, 218-248.

Kotchick, B. A., Shaffer, A., Forehand, R., \& Miller, K. S. (2001). Adolescent sexual risk behavior: A multi-system perspective. Clinical Psychology Review, 21, 493-519.

Lahey, B. B., Van Hulle, C. A., \& Waldman, I. D. (2006). Testing descriptive hypotheses regarding sex differencecs in the development of conduct problems and delinquency. Journal of Abnormal Child Psychology, 34, 737-755.

Lynch, S. K., Turkheimer, E., D'Onofrio, B. M., Mendle, J., Emery, R. E., Slutske, W., et al. (2006). A genetically informed study of the association between harsh punishment and offspring behavioral problems. Journal of Family Psychology, 20, 190-198.

Mandara, J., Murray, C., \& Bangi, A. K. (2003). Predictors of African American adolescent sexuality: An ecological framework. Journal of Black Psychology, 29, 337-356.

McLanahan, S. S. (1999). Father absence and the welfare of children. In E. M. Hetherington (Ed.), Coping with divorce, single parenting, and remarriage (pp. 117-145). Mahwah, NJ: Erlbaum.

Meier, A. M. (2007). Adolescent first sex and subsequent mental health. American Journal of Sociology, 112, 18111847.

Mendle, J., Turkheimer, E., D'Onofrio, B. M., Lynch, S. K., Emery, R. E., Slutske, W., et al. (2006). Family 
structure and age at menarche: A children of twins approach. Developmental Psychology, 42, 535-542.

Miller, B. C., Norton, M. C., Curtis, T., Hill, E. J., Schvaneveldt, P., \& Young, M. H. (1997). The timing of sexual intercourse among adolescents: Family, peer, \& other antecedents. Youth and Society, 29, 54-83.

Mustanski, B. S., Viken, R. J., Kaprio, J., Pulkkinen, L., \& Rose, R. J. (2004). Genetic and environmental influences on pubertal development: Longitudinal data from Finnish twins at ages 11 and 14. Developmental Psychology, 40, 1188-1198.

Mustanski, B. S., Viken, R. J., Kaprio, J., Winter, T., \& Rose, R. J. (2007). Sexual behavior in young adulthood: A population-based twin study. Health Psychology, 26, 610-617.

Newcomer, S., \& Udry, J. R. (1987). Parental marital status effects on adolescent sexual behavior. Journal of Marriage and the Family, 49, 235-240.

Neiss, M., Rowe, D. C., \& Rodgers, J. L. (2002). Does education mediate the relationship between IQ and age of first birth? A behavioural genetic analysis. Journal of Biosocial Science, 34, 259-275.

Plomin, R. (1990). Nature and nurture: An introduction to human behavioral genetics. Pacific Grove, CA: Brooks/Cole.

Quinlan, R. J. (2003). Father absence, parental care, \& female reproductive development. Evolution and Human Behavior, 24, 376-390.

Raudenbush, S. W., \& Bryk, A. S. (2002). Hierarchical linear models (2nd ed.). Thousand Oaks, CA: Sage.

Rodgers, J. L. (1996). NLSY Youth linking algorithm. Unpublished manuscript, University of Oklahoma at Norman.

Rodgers, J. L., Johnson, A. B., \& Bard, D. E. (2005). NSLYChildren/Young Adult (1986-2000) kinship linking algorithm. Unpublished manuscript, University of Oklahoma at Norman.

Rodgers, J. L., Rowe, D. C., \& Buster, M. (1999). Nature, nurture, and first sexual intercourse in the U.S.A.: Fitting behavioral genetic models to NLSY kinship data. Journal of Biosocial Science, 31, 29-41.

Rodgers, J. L., Rowe, D. C., \& Li, C. (1994). Beyond nature vs. nurture: DF analyses of nonshared influences on problem behaviors. Developmental Psychology, 30, 374384.

Rowe, D. C. (2002). On genetic variation and age at first sexual intercourse: A critique of the Belsky-Draper hypothesis. Evolution and Human Behavior, 23, 365-372.

Smith, C. A., \& Farrington, D. P. (2004). Continuity in antisocial behavior and parenting acrossthree generations. Journal of Child Psychology and Psychiatry, 45, 230-247.
Spiegelhalter, D. J., Best, N. G., Carlin, B. P., \& van der Linde, A. (2002). Bayesian measures of model complexity and fit. Journal of the Royal Statistical Society: Series B. Statistical Modeling, 64, 583-639.

Stone, N., \& Ingham, R. (2002). Factors affecting British teenagers' contraceptive use at first intercourse: The importance of partner communication. Perspectives on Sexual and Reproductive Health, 34, 191-197.

Stouthamer-Loeber, M., \& Wei, E. H. (1998). The precursors of young fatherhood and its effects on delinquency of teenage males. Journal of Adolescent Health, 22, 56-65.

Thornton, A., \& Camburn, D. (1987). The influence of the family on premarital sexual attitudes and behavior. Demography, 24, 323-340.

Tither, J. M., \& Ellis, B. J. (2008). Impact of fathers on daughters' age at menarche: A genetically- and environmentally-controlled sibling study. Developmental Psychology, 44, 1409-1420.

Udry, J. R. (1979). Age at menarche, at first intercourse, \& at first pregnancy. Journal of Biosocial Science, 11, 433441.

Upchurch, D. M., Aneshensel, C. S., Sucoff, C. S., \& LevyStorms, L. (1999). Neighborhood and family contexts of adolescent sexual activity. Journal of Marriage and the Family, 61, 920-933.

Upchurch, D. M., Lillard, L. A., Aneshensel, C. S., \& Li, N. F. (2002). Inconsistencies in reporting the occurrence and timing of first intercourse among adolescents. Journal of Sex Research, 39, 197-206.

van den Oord, E. J. C. G., \& Rowe, D. C. (2000). Racial differences in birth health risk: A quantitative genetic approach. Demography, 37, 285-298.

Van Hulle, C. A., Rodgers, J. L., D'Onofrio, B. M., Waldman, I. D., \& Lahey, B. B. (2007). Sex differences in the causes of self-reported adolescent delinquency. Journal of Abnormal Psychology, 116, 236-248.

Wellings, K., Nanchahal, K., Macdowall, W., McManus, S., Erens, B., Mercer, C. H., et al. (2001). Sexual behaviour in Britain: Early heterosexual experience. Lancet, 358, 843-1850.

Wight, D., Williamson, L., \& Henderson, M. (2006). Parental influences on young people's sexual behaviour: A longitudinal analysis. Journal of Adolescence, 29, 473-494.

Woodward, L., \& Fergusson, D. (1999). Early conduct problems and later risk of teenage pregnancy in girls. Development and Psychopathology, 11, 127-141.

Wu, L. L., \& Thomson, E. (2001). Race differences in family experience and early sexual initiation: Dynamic models of family structure and family change. Journal of Marriage and the Family, 63, 682-696. 